\title{
Nurse delivered focused echocardiography to determine intravascular volume status in a deployed maritime critical care unit
}

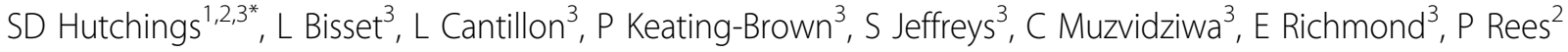 \\ From ESICM LIVES 2015 \\ Berlin, Germany. 3-7 October 2015
}

\section{Introduction}

Focused echocardiography is increasingly used by clinicians in the management of critically ill patients and has been adopted by the Defence Medical Services as a tool to guide flow assessment and resuscitation in deployed critical care.

\section{Objectives}

We aimed to explore whether two focused echo techniques; Inferior Vena Cava (IVC) and Left Ventricular Outflow Tract (LVOT) Velocity Time Integer (VTi) variability could be taught to a group of critical care nurse who had no previous exposure to ultrasound imaging.

\section{Methods}

Ethical approval was waived for this service improvement study. After a five week program of training validation was carried out on healthy volunteers. The mentor, an accredited focused echo trainer, and six nurses performed a total of 48 scans on 11 volunteers. The mentor and students acquired subcostal long axis and apical five chamber windows using a high frequency linear ultrasound probe (Sonosite M Turbo, P21-51x transducer). Mean values from three measurements were obtained for IVC diameter and LVOT VTi. Minimum and maximum values were recorded for both variables across a full respiratory cycle. Echo images were saved and at least two images for each student were reviewed offline by an accredited echo training supervisor.

\section{Results}

In all cases students were able to obtain adequate echo windows. There was good correlation between values recorded by the mentor and students for both IVC diameter $(\mathrm{r}=0.90, \mathrm{p}<0.001)$ and LVOT VTi $(\mathrm{r}=0.77, \mathrm{p}<$ 0.001). Bland Altman analysis showed good correlation with minimal bias for VTi measurements. There was, however, some increase in bias for IVC measurements below $1.2 \mathrm{~cm}$.

\section{Conclusion}

We demonstrated that two focused echo techniques for assessing intravascular volume status could be acquired by specialist nurses, with no previous experience, in a relatively short time and that results were comparable to those produced by an experienced practitioner. These results will need to be replicated in a clinical setting before being adopted into practice.

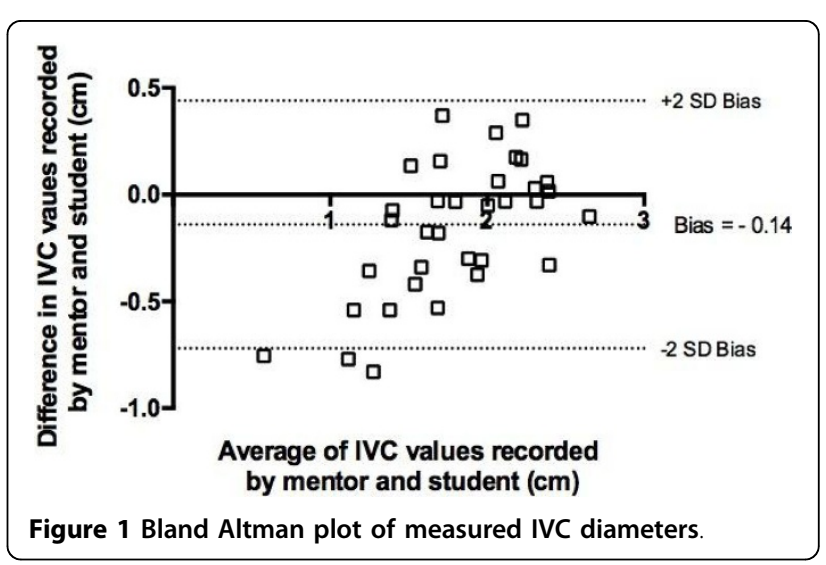




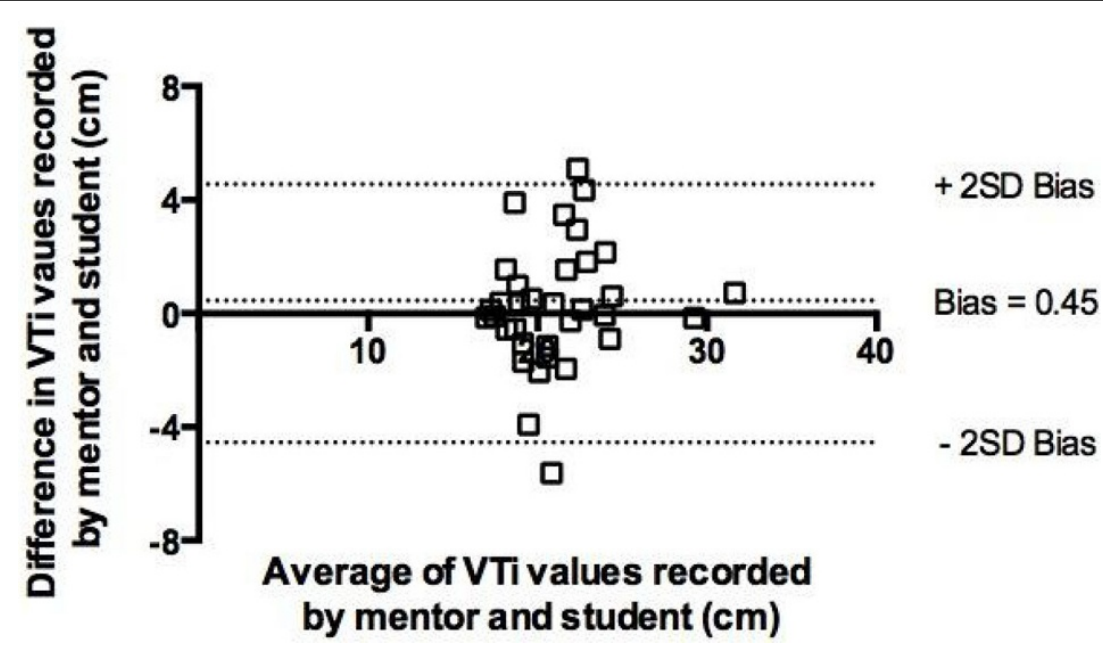

Figure 2 Bland Altman plot of LVOT VTi measurements.

\section{Authors' details}

${ }^{1}$ Kings College Hospital, Critical Care, London, United Kingdom. ${ }^{2}$ Royal Centre for Defence Medicine, Birmingham, United Kingdom. ${ }^{3}$ Primary

Casualty Receiving Facility, Intensive Care Unit, Royal Navy, United Kingdom.

Published: 1 October 2015

doi:10.1186/2197-425X-3-S1-A919

Cite this article as: Hutchings et al:: Nurse delivered focused

echocardiography to determine intravascular volume status in

a deployed maritime critical care unit. Intensive Care Medicine

Experimental 2015 3(Suppl 1):A919.

Submit your manuscript to a SpringerOpen ${ }^{\circ}$ journal and benefit from:

- Convenient online submission

- Rigorous peer review

- Immediate publication on acceptance

- Open access: articles freely available online

- High visibility within the field

- Retaining the copyright to your article 